\title{
Phylogenetic Relationships among Members of the Ascomycetous Yeast Genera Brettanomyces, Debaryomyces, Dekkera, and Kluyveromyces Deduced by Small-Subunit rRNA Gene Sequences
}

\author{
JUNPENG CAI, ${ }^{1}$ IAN N. ROBERTS, ${ }^{2}$ AND MATTHEW D. COLLINS ${ }^{1 *}$ \\ BBSRC Institute of Food Research, Reading Laboratory, Reading, RG6 6BZ, ${ }^{1}$ and BBSRC Institute \\ of Food Research, Norwich Laboratory, Norwich, NR4 $7 U A,{ }^{2}$ United Kingdom
}

\begin{abstract}
A molecular systematic investigation of members of the ascomycetous yeast genera Brettanomyces, Debaryomyces, Dekkera, and Kluyveromyces was performed by using $18 S$ rRNA gene sequence analysis. Our comparative sequence analysis revealed that Brettanomyces anomalus and Brettanomyces bruxellensis were closely related to one another and also to their teleomorphs, Dekkera anomala and Dekkera bruxellensis, respectively. Together with Dekkera custersiana and Dekkera naardenensis, these four species formed a stable and distinct phylogenetic group. The three representative species of the genus Debaryomyces examined (viz., Debaryomyces castellii, Debaryomyces hansenii, and Debaryomyces udenii) were found to be genealogically highly related to each other and exhibited a specific phylogenetic affinity (level of sequence similarity, approximately 99.2\%) with Candida guilliermondii (teleomorph, Pichia guilliermondii). Debaryomyces species and $C$. guilliermondii formed a distinct phylogenetic group, which displayed a significant association with a phylogenetically coherent cluster encompassing Lodderomyces elongisporus, Candida albicans, and four other Candida species. In contrast to the situation with the genera Brettanomyces and Debaryomyces, the genus Kluyveromyces displayed very marked phylogenetic heterogeneity. Kluyveromyces polysporus, the type species of the genus Kluyveromyces, and six other Kluyveromyces species (viz., Kluyveromyces africanus, Kluyveromyces delphensis, Kluyveromyces lodderae, Kluyveromyces thermotolerans, Kluyveromyces waltii, and Kluyveromyces yarrowii) were phylogenetically intermixed with species of the genera Zygosaccharomyces, Saccharomyces, and Torulaspora. In contrast, Kluyveromyces aestuarii, Kluyveromyces dobzhanskii, Kluyveromyces lactis, Kluyveromyces wickerhamii, and three Kluyveromyces marxianus varieties, along with their anamorph, Candida kefyr, formed a highly stable monophyletic group worthy of separate generic status. Kluyveromyces blattae and Kluyveromyces phaffii formed two distinct phylogenetic lines that did not exhibit particularly close affinity with each other or other ascomycetous yeast genera. Our phylogenetic findings are discussed in the context of the results of other genotypic and phenotypic studies.
\end{abstract}

The yeasts constitute a unique group of fungi that are characterized by vegetative growth that is predominantly unicellular and by the formation of sexual states which are not enclosed in fruiting bodies. The potential phylogenetic diversity of these morphologically simple fungi is illustrated by the fact that some species have ascomycetous life cycles, whereas others have basidiomycetous life cycles; i.e., different yeasts are members of fundamentally different subdivisions of the fungi. In contrast to the situation with bacteria, in which knowledge of evolutionary relationships has been revolutionized by smallsubunit rRNA sequence analyses (28), information on the phylogeny of yeasts is limited (12). Although in recent years we have seen an increasing number of phylogenetic investigations involving yeasts $(1,12,29-31)$, many of these studies have been based on determinations of relatively small parts (often a few hundred nucleotides) of the small- and/or large-subunit rRNA, an approach which is inherently more prone to error than full sequence analysis (8). The number of known complete (or almost complete) yeast rRNA sequences is still very limited (less than 100 small-subunit rRNA yeast sequences, compared with several thousand bacterial sequences). In order to better understand the evolutionary relationships among the yeasts and to construct more stable and robust phylogenetic frame-

${ }^{*}$ Corresponding author. Mailing address: BBSRC Institute of Food Research, Reading Laboratory, Earley Gate, Whiteknights Road, Reading, RG6 6BZ, United Kingdom. Phone: 44-1734-357226. Fax: 44-1734-267917. works, many more complete rRNA sequences must be determined $(6,8,27)$. In this study we used PCR amplification and direct sequencing to determine the almost complete smallsubunit rRNA gene sequences of 28 ascomycetous yeast strains belonging to the genera Brettanomyces, Debaryomyces, Dekkera, and Kluyveromyces. In this paper the results of a comparative rRNA sequence analysis are presented and inferred evolutionary relationships are discussed in the context of other taxonomic criteria.

\section{MATERIALS AND METHODS}

Yeast strains and cultivation. The yeast strains examined in this study are listed in Table 1. Strains were obtained from the National Collection of Yeast Cultures, Norwich, United Kingdom, and the Centraalbureau voor Schimmelcultures, Delft, The Netherlands. All strains were grown on YM agar $(0.3 \%$ yeast extract, $0.3 \%$ malt extract, $0.5 \%$ peptone, $1 \%$ glucose, $20 \%$ agar; pH 5.5 ) at $25^{\circ} \mathrm{C}$.

DNA isolation and purification. To prepare yeast genomic DNA, we used the methods of Sambrook et al. (20) and Philippsen et al. (19), with some modifications. The procedure which we used is described below. Yeast cells were harvested from YM agar plates, resuspended in lysis buffer (1 M sorbitol, $0.1 \mathrm{M}$ EDTA; $\mathrm{pH} 8.0$ ), and frozen at $-70^{\circ} \mathrm{C}$. After the cells were thawed at room temperature, $75 \mu \mathrm{l}$ of a $1,000-\mathrm{U} / \mathrm{ml}(67-\mathrm{mg} / \mathrm{ml})$ lyticase solution (Sigma) was added to each preparation, and the preparation was incubated at $37^{\circ} \mathrm{C}$ for $2 \mathrm{~h}$. After $70 \mu \mathrm{l}$ of a $20 \%$ sodium dodecyl sulfate solution (final concentration, $0.3 \%$ ), $20 \mu \mathrm{l}$ of a $1-\mu \mathrm{g} / \mathrm{ml}$ RNase A solution, and $30 \mu \mathrm{l}$ of a $10-\mu \mathrm{g} / \mathrm{ml}$ proteinase K solution were added, the lysis solution was incubated at $37^{\circ} \mathrm{C}$ for $2 \mathrm{~h}$ and extracted three times with phenol-chloroform. DNA was precipitated from the aqueous phase by adding 2 volumes of ice-cold absolute ethanol and 0.1 volume of $3 \mathrm{M}$ sodium acetate ( $\mathrm{pH} 4.8)$. Pelleted DNA was rinsed with $80 \%$ ethanol and dried in air. The DNA was resuspended in $1 \times$ TE buffer ( $\mathrm{pH} \mathrm{8.0)}$, assayed at 260 and $280 \mathrm{~nm}$ with a model MPS-2000 Shimadzu spectrophotometer, and diluted for PCR amplification. 
TABLE 1. Yeast strains compared in this study and their small-subunit rRNA gene sequence accession numbers

\begin{tabular}{|c|c|c|}
\hline Species or variety & Strain $^{a}$ & $\begin{array}{c}\text { EMBL and/or } \\
\text { GenBank } \\
\text { accession no. }\end{array}$ \\
\hline Ascosphaera apis & Unknown & M83264 \\
\hline Athelia bombacina & Unknown & M55638 \\
\hline Aureobasidium pullulans & Unknown & M55639 \\
\hline Blastomyces dermatidis & Unknown & M63096 \\
\hline Boletus santanas & TDB- 1000 & M94337 \\
\hline Brettanomyces anomalus & NCYC 615 & $\mathrm{X} 83828^{b}$ \\
\hline Brettanomyces anomalus & NCYC 749 & $\mathrm{X} 83816^{b}$ \\
\hline Brettanomyces anomalus & NCYC $449^{\mathrm{T}}$ & $\mathrm{X} 83818^{b}$ \\
\hline Brettanomyces bruxellensis & NCYC $370^{T}$ & $\mathrm{X} 83815^{b}$ \\
\hline Brettanomyces bruxellensis & NCYC 362 & $\mathrm{X} 83814^{b}$ \\
\hline Bulleromyces albus & MUCL 30301 & X60179 \\
\hline Candida albicans & MUCL 29800 & X53497 \\
\hline Candida glabrata & CBS $138^{\mathrm{T}}$ & X51831 \\
\hline Candida guilliermondii & ATCC $6260^{\mathrm{T}}$ & M60304 \\
\hline Candida holmii & $\mathrm{NCYC} 137^{\mathrm{T}}$ & $\times 78601$ \\
\hline $\begin{array}{l}\text { Candida kefyr (Candida } \\
\text { pseudotropicalis) }\end{array}$ & ATCC $4135^{\mathrm{T}}$ & M60303 \\
\hline Candida knusei & MUCL 29849 & M55528 \\
\hline Candida maltosa & IAM 12247 & D14593 \\
\hline Candida parapsilosis & ATCC $22019^{\mathrm{T}}$ & M60307 \\
\hline Candida tropicalis & MUCL 30002 & M55527 \\
\hline Candida viswanathii & ATCC $22891^{\mathrm{T}}$ & M60309 \\
\hline Clavispora lusitaniae & MUCL 29855 & M55526 \\
\hline Coprinus cinereus & Unknown & M92991 \\
\hline Cryptococcus neoformans & ATCC 24067 & L05428 \\
\hline Cystofilobasidium capitatum & IAM $13521^{\mathrm{T}}$ & D12801 \\
\hline Debaryomyces castellii & NCYC $604^{\mathrm{T}}$ & $\mathrm{X} 83819^{b}$ \\
\hline Debaryomyces hansenii & MUCL 29826 & X58053 \\
\hline Debaryomyces udenii & NCYC $2394^{\mathrm{T}}$ & $\mathrm{X} 83821^{b}$ \\
\hline Dekkera anomala & CBS $8139^{\mathrm{T}}$ & $\mathrm{X} 83820^{b}$ \\
\hline Dekkera bruxellensis & MUCL 27700 & X58052 \\
\hline Dekkera custersiana & CBS $4805^{\mathrm{T}}$ & $\mathrm{X} 83817^{b}$ \\
\hline Dekkera naardenensis & CBS $6042^{\mathrm{T}}$ & $\mathrm{X} 85110^{b}$ \\
\hline Dipodascopsis uninucleata & Unknown & U00969 \\
\hline Endomyces geotrichum & Unknown & U00974 \\
\hline Endomyces fibuliger & MUCL 14481 & X69841 \\
\hline Eremascus albus & Unknown & M83258 \\
\hline Filobasidium neoformans & IAM $14211^{T}$ & D12804 \\
\hline Galactomyces geotrichum & MUCL 28959 & X69842 \\
\hline Glaziella aurantiaca & UME 29396 & $\mathrm{Z} 49753$ \\
\hline Hanseniaspora uvarum & MUCL 30663 & X69844 \\
\hline Kluyveromyces aestuarii & CBS $4438^{\mathrm{T}}$ & $\mathrm{X} 89520^{b}$ \\
\hline Kluyveromyces africanus & CBS $2517^{T}$ & $\mathrm{X} 89519^{b}$ \\
\hline Kluyveromyces blattae & CBS $6284^{\mathrm{T}}$ & $\mathrm{X} 89521^{b}$ \\
\hline Kluyveromyces cellobiovorus & CBS $7153^{\mathrm{T}}$ & $\mathrm{X} 89518^{b}$ \\
\hline Kluyveromyces delphensis & $\mathrm{NCYC} 768^{\mathrm{T}}$ & $\mathrm{X} 83823^{b}$ \\
\hline Kluyveromyces dobzhanskii & NCYC $538^{\mathrm{T}}$ & $\mathrm{X} 83822^{b}$ \\
\hline Kluyveromyces lactis & IFO 1267 & X51830 \\
\hline Kluyveromyces lodderae & $\mathrm{NCYC} 1417^{\mathrm{T}}$ & $\mathrm{X} 83824^{b}$ \\
\hline $\begin{array}{l}\text { Kluyveromyces marxianus var. } \\
\text { bulgaricus }\end{array}$ & NCYC $970^{\mathrm{T}}$ & $\mathrm{X} 89524^{b}$ \\
\hline $\begin{array}{l}\text { Kluyveromyces maxianus var. } \\
\text { marxianus }\end{array}$ & CBS $712^{\mathrm{T}}$ & $\mathrm{X} 89523^{b}$ \\
\hline $\begin{array}{l}\text { Kluyveromyces marxianus var. } \\
\text { wikenii }\end{array}$ & CBS $5671^{\mathrm{T}}$ & $\mathrm{X} 89522^{b}$ \\
\hline Kluyveromyces phaffii & CBS $4417^{\mathrm{T}}$ & $\mathrm{X} 89525^{b}$ \\
\hline Kluyveromyces polysporus & NCYC $523^{\mathrm{T}}$ & $\mathrm{X} 83825^{b}$ \\
\hline Kluyveromyces thermotolerans & CBS $6340^{\mathrm{T}}$ & $\mathrm{X} 89526^{b}$ \\
\hline Kluyveromyces waltii & CBS $6430^{\mathrm{T}}$ & $\mathrm{X} 89527^{h}$ \\
\hline Kluyveromyces wickerhamii & NCYC $546^{\mathrm{T}}$ & $\mathrm{X} 83826^{b}$ \\
\hline Kluyveromyces yarrowii & CBS $8242^{\mathrm{T}}$ & $\mathrm{X} 89528^{b}$ \\
\hline Lepiota procera & Unknown & L36659 \\
\hline Leucosporidium lari-marini & IAM $14213^{\mathrm{T}}$ & D12805 \\
\hline Leucosporidium scottii & MUCL 28629 & X53499 \\
\hline Lodderomyces elongisporus & CBS $2605^{T}$ & $X 78600$ \\
\hline
\end{tabular}

TABLE 1-Continued

\begin{tabular}{|c|c|c|}
\hline Species or variety & Strain $^{a}$ & $\begin{array}{l}\text { EMBL and/or } \\
\text { GenBank } \\
\text { accession no. }\end{array}$ \\
\hline Metschnikowia bicuspidata & MUCL 31145 & $\mathrm{X} 69846$ \\
\hline Mrakia frigida & IAM $14136^{\mathrm{T}}$ & D12802 \\
\hline Neolecta vitellina & UME 29192 & Z27393 \\
\hline Pichia angusta & ATCC $34438^{\mathrm{T}}$ & M60310 \\
\hline Pichia anomala & MUCL 28639 & X58054 \\
\hline Pichia membranaefaciens & MUCL 30004 & X58055 \\
\hline Plectania nigrella & UME 29220 & Z27408 \\
\hline Pneumocystis carinii & Unknown & $\mathrm{X} 12708$ \\
\hline Rhodotorula glutinis & MUCL 30249 & $\mathrm{X} 60180$ \\
\hline Rhodotorula graminis & NCYC $502^{\mathrm{T}}$ & $\mathrm{X} 83827^{h}$ \\
\hline Rhodotorula mucilaginosa & $\mathrm{NCYC} 63^{\mathrm{T}}$ & $\mathrm{X} 84326^{b}$ \\
\hline Rhodosporidium dacryoidum & IAM 13522 & D13459 \\
\hline Rhodosporidium toruloides & IAM $13469^{\mathrm{T}}$ & D12806 \\
\hline Saccharomyces cerevisiae & Unknown & M27607 \\
\hline Saccharomycodes ludwigii & MUCL 31269 & $\mathrm{X} 69843$ \\
\hline Saccharomycopsis capsularis & MUCL 27839 & X69847 \\
\hline Saitoella complicata & Unknown & D01174 \\
\hline $\begin{array}{l}\text { Schizosaccharomyces japoni- } \\
\text { cus var. versatilis }\end{array}$ & Unknown & $\mathrm{Z} 32848$ \\
\hline Schizosaccharomyces pombe & Unknown & X54866 \\
\hline Schizophyllum commune & Unknown & X54865 \\
\hline Spongipellis unicolor & Unknown & M59760 \\
\hline Sporidiobolus johnsonii & Unknown & L22261 \\
\hline Sporobolomyces roseus & MUCL $30251^{\mathrm{T}}$ & $\mathrm{X} 60181$ \\
\hline Taphrina deformans & ATCC 34556 & U00971 \\
\hline Taphrina populina & CBS $337.55^{\mathrm{T}}$ & D14165 \\
\hline Taphrina wiesneri & Unknown & D12531 \\
\hline Thanatephorus praticola & Unknown & M92990 \\
\hline Torulaspora delbrueckii & MUCL 27816 & X53496 \\
\hline Torulaspora globosa & NCYC $820^{\mathrm{T}}$ & X84639 \\
\hline Torulaspora pretoriensis & $\mathrm{NCYC} 524^{\mathrm{T}}$ & $\mathrm{X} 84638$ \\
\hline Trichosporon cutaneum & MUCL $30308^{c}$ & X60182 \\
\hline Urnula hiemalis & UME 30174 & Z49754 \\
\hline Ustilago hordei & Unknown & U00973 \\
\hline Ustilago maydis & MUCL 30488 & X62396 \\
\hline Waltomyces lipofer & MUCL 27781 & X69848 \\
\hline Yarrowia lipolytica & ATCC $18942^{\mathrm{T}}$ & M60312 \\
\hline Zygosaccharomyces bailii & NCYC $1416^{\mathrm{T}}$ & X91083 \\
\hline Zygosaccharomyces bisponus & NCYC $1495^{\mathrm{T}}$ & X91084 \\
\hline Zygosaccharomyces cidri & $\mathrm{NCYC} 1567^{\mathrm{T}}$ & X91085 \\
\hline Zygosaccharomyces fermentati & CBS $707^{\mathrm{T}}$ & $X 77930$ \\
\hline Zygosaccharomyces florentinus & CBS $746^{\top}$ & X91086 \\
\hline Zygosaccharomyces mellis & NCYC $2403^{T}$ & X90755 \\
\hline $\begin{array}{l}\text { Zygosaccharomyces micro- } \\
\text { ellipsoides }\end{array}$ & $\operatorname{CBS} 427^{\mathrm{T}}$ & $\mathrm{X} 90756$ \\
\hline Zygosaccharomyces mrakii & CBS $4218^{\mathrm{T}}$ & $\mathrm{X} 90757$ \\
\hline Zygosaccharomyces rouxii & NCYC $568^{\mathrm{T}}$ & $\mathrm{X} 90758$ \\
\hline
\end{tabular}

${ }^{a}$ NCYC, National Collection of Yeast Cultures, Norwich, United Kingdom; CBS, Centraalbureau voor Schimmelcultures, Delft, The Netherlands; ATCC, American Type Culture Collection, Rockville, Md.; MUCL, Mycothèque de I'Université Catholique, Louvain-la-Neuve, Belgium; IAM, Institute of Applied Microbiology, Tokyo, Japan; IFO, Institute of Fermentation, Osaka, Japan.

${ }^{b}$ Sequence determined in this study.

${ }^{c}$ Neotype strain.

PCR amplification and determination of the $18 S$ rRNA gene sequence. The procedure used to amplify $18 \mathrm{~S}$ rRNA genes was the procedure described by James et al. (8), except that in this study $200 \mathrm{ng}$ of genomic DNA rather than a single colony was used as the PCR template. The three pairs of PCR amplification primers used were P108 plus M2130, P1190 plus M3490, and P2130 plus M3989 (8) (Table 2). After we confirmed that successful amplification had occurred, the PCR products were purified by using a Wizard PCR cleaning kit (Promega, Madison, Wis.) as recommended by the manufacturer. Direct sequencing of the purified PCR products was carried out by using $\alpha-{ }^{35} \mathrm{~S}$-labeled dATP and a Sequenase version 2.0 sequencing kit (U.S. Biochemical, Amersham, United Kingdom) as described by Hutson et al. (7). The primers used to determine 18S rRNA gene sequences are shown in Table 2. Both strands of the ribosomal DNA (rDNA) were sequenced. 
TABLE 2. Primers used for direct sequencing of small-subunit rRNA genes

\begin{tabular}{|c|c|c|}
\hline Primer & Primer sequence $\left(5^{\prime}-3^{\prime}\right)$ & $\begin{array}{l}\text { Position (Saccha- } \\
\text { romyces cerevisiae } \\
\text { numbering) }\end{array}$ \\
\hline P108 & ACCTGGTTGATCCTGCCAGT & $2-21$ \\
\hline P130 & GTCTCAAAGATTAAGCCATG & $34-53$ \\
\hline $\mathrm{F} 150$ & ACTACATGGATA(A/T)C(C/T)GTGC & $150-169$ \\
\hline R150 & CCAC(G/A)G(T/A)TATCCATGTAGT & $169-150$ \\
\hline M760 & CCGTTGAAACCATGGTAG & $356-339$ \\
\hline P1190 & CAATTGGAGGGCAAGTCTGG & $543-562$ \\
\hline M1190 & CCAGACTTGCCCTCCAATTG & $562-543$ \\
\hline F600 & CAGCTCCA(A/G)TAGCGTATA & $600-618$ \\
\hline R600 & TATACGCTA(T/C)TGGAGCTG & $618-600$ \\
\hline F800 & CATGGAATAAT(A/G)GAATAGG & $800-819$ \\
\hline $\mathrm{R} 800$ & ССТАТТС(Т/С)АТТАТТССАТG & $819-800$ \\
\hline P2130 & GGTGAAATTCTTGGATTTATTG & $900-921$ \\
\hline M2130 & CAATAAATCCAAGAATTTCACC & $921-900$ \\
\hline P2540 & GGAGTATGGTCGCAAGGCTG & $1108-1127$ \\
\hline M2540 & CAGCCTTGCGACCATACTCC & 1127-1108 \\
\hline M3490 & TCAGTGTAGCGCGCGTGCGG & $1473-1454$ \\
\hline M3793 & CGACGGGCGGTGTGTACAAAG & $1643-1623$ \\
\hline FOR3 & GCTTAGTGAGGCCTC(C/A)GG & $1661-1678$ \\
\hline M3989 & CTACGGAAACCTTGTTACGACT & $1775-1754$ \\
\hline
\end{tabular}

Analysis of sequence data. The 18S rRNA gene sequence data were processed by using the Wisconsin Molecular Biology Software Package (2), version 7.2. The $2818 \mathrm{~S}$ rDNA sequences which we determined were aligned with the sequences of 88 other ascomycetes and basidiomycetes retrieved from the EMBL data library by using the multiple-sequence alignment program PILEUP (4). The alignments were adjusted manually. An unrooted phylogenetic tree was constructed by using the NEIGHBOR-JOINING program contained in the PHYLIP phylogeny inference package, version 3.5 (3). The confidence values of branches were determined by performing a bootstrap analysis in which 500 replicates were used (3). In addition, a parsimony analysis (3) was performed with a reduced data set comprising species belonging to the subclass Hemiascomycetidae.

Nucleotide sequence accession numbers. The 18S rRNA gene sequences which we determined have been deposited in the EMBL data library under the accession numbers shown in Table 1.

\section{RESULTS AND DISCUSSION}

The small-subunit (18S) rRNA gene sequences of 28 yeast strains were amplified in vitro by PCR, and their nucleotide sequences were determined directly. These newly determined sequences were approximately 1,800 nucleotides long and represented more than $99 \%$ of the $18 \mathrm{~S}$ rRNA primary structure. The sequences which we determined were aligned with 88 ascomycetous and basidiomycetous complete or nearly complete 18S rRNA sequences retrieved from the GenBank and EMBL data libraries. Levels of sequence similarity were calculated, and the derived distances were used to infer phylogenetic relationships. Figure 1 is an unrooted tree that was constructed by using the neighbor-joining method and shows the phylogenetic relationships of the yeasts and fungi which we compared. The confidence values for individual branches of the tree were determined by performing a bootstrap analysis in which 500 bootstrap trees were generated from resampled data. The phylogenetic relationships of species belonging to the subclass Hemiascomycetidae were also investigated by performing a parsimony analysis. All of the significant associations (bootstrap values, $\geq 90 \%$ [Fig. 1]) inferred by the neighbor- joining method were confirmed by this method. As shown in Fig. 1, the ascomycetous and basidiomycetous species formed two well-separated lineages. All of the yeast strains sequenced were recovered within subclass Hemiascomycetidae of class Ascomycetes. For a detailed discussion of the subclass Euascomycetidae, see reference 27.

Genera Brettanomyces and Dekkera. The three Brettanomyces anomalus strains examined (NCYC 615, NCYC 749, and NCYC $449^{\mathrm{T}}$ [ $\mathrm{T}=$ type strain]) had identical 18S rRNA gene sequences. However, the 18S rRNA gene of Brettanomyces anomalus differed at two nucleotide positions from the $18 \mathrm{~S}$ rRNA gene of its teleomorph, Dekkera anomala. Similarly, the 18S rRNA gene sequences of the two Brettanomyces bruxellensis strains examined (NCYC 362 and NCYC 370 ) were identical but differed at seven nucleotide positions from the previously published sequence of the teleomorph Dekkera bruxellensis (6). Although Brettanomyces anomalus (including Dekkera anomala) and Brettanomyces bruxellensis (including Dekkera bruxellensis) are genealogically distinct, it is evident from the level of sequence divergence (approximately 0.1 to $0.4 \%$ ) and tree resampling measurements (bootstrap value, 100\%) that these organisms are phylogenetically closely related species. These findings are in accordance with the results of recent partial small- and large-subunit rRNA sequence $(1,30)$ and rDNA restriction fragment length polymorphism analyses (18). We found that the strains of Dekkera custersiana and Dekkera naardenensis which we examined were also specifically, albeit more distantly, related to Brettanomyces (Dekkera) anomalus and Brettanomyces (Dekkera) bruxellensis. Particularly noteworthy were the much lower levels of sequence relatedness (approximately 94.8 to $95.4 \%$ ) (Table 3) between Dekkera custersiana and other Brettanomyces (Dekkera) species, which is consistent with the data of Yamada et al. (30) and Boekhout et al. (1) based on partial rRNA sequence analyses. Indeed, Yamada et al. (30) concluded that Dekkera custersiana should be assigned a teleomorphic genus separate from the genus Dekkera van der Walt. Despite the greater level of sequence divergence and somewhat peripheral position of Dekkera custersiana, it is evident from the results of our treeing analysis of nearly complete $18 \mathrm{~S}$ rRNA gene sequences that this species, together with Brettanomyces (Dekkera) anomalus, Brettanomyces (Dekkera) bruxellensis, and Dekkera naardenensis, forms a significant phylogenetic group (bootstrap value, 100\%). Furthermore, because of the deeper branching position of Dekkera naardenensis (Fig. 1), any phylogenetic proposal to assign Dekkera custersiana to a separate genus (30) would also mean that a new genus would have to be created for Dekkera naardenensis. Although Eeniella nana was not included in our analysis, it is pertinent to note that partial 26S rRNA sequencing data (1) indicate that this species also forms a deep and distinct subline within the genus Brettanomyces.

Genus Debaryomyces. We also determined the phylogenetic relationships of three representative species of the genus $D e$ baryomyces (Debaryomyces castellii, Debaryomyces hansenii, and Debaryomyces udenii). These three species were found to be genealogically very closely related (levels of sequence similarity; 99.2 to $99.6 \%$ ) (Table 4). The close association of these species is consistent with the results of previous studies $(13,31)$ based on partial small- and large-subunit rRNA sequence data. It was evident from our treeing analysis data that Candida

FIG. 1. Dendrogram showing the relationships among species of the genera Brettanomyces, Debaryomyces, Dekkera, and Kluyveromyces and related taxa. The tree is based on 18S rRNA gene sequence data and was constructed by using the neighbor-joining method. Bootstrap values were calculated from 500 trees. Organisms whose $18 \mathrm{~S}$ rRNA sequences were determined in this study are shown in boldface type. 


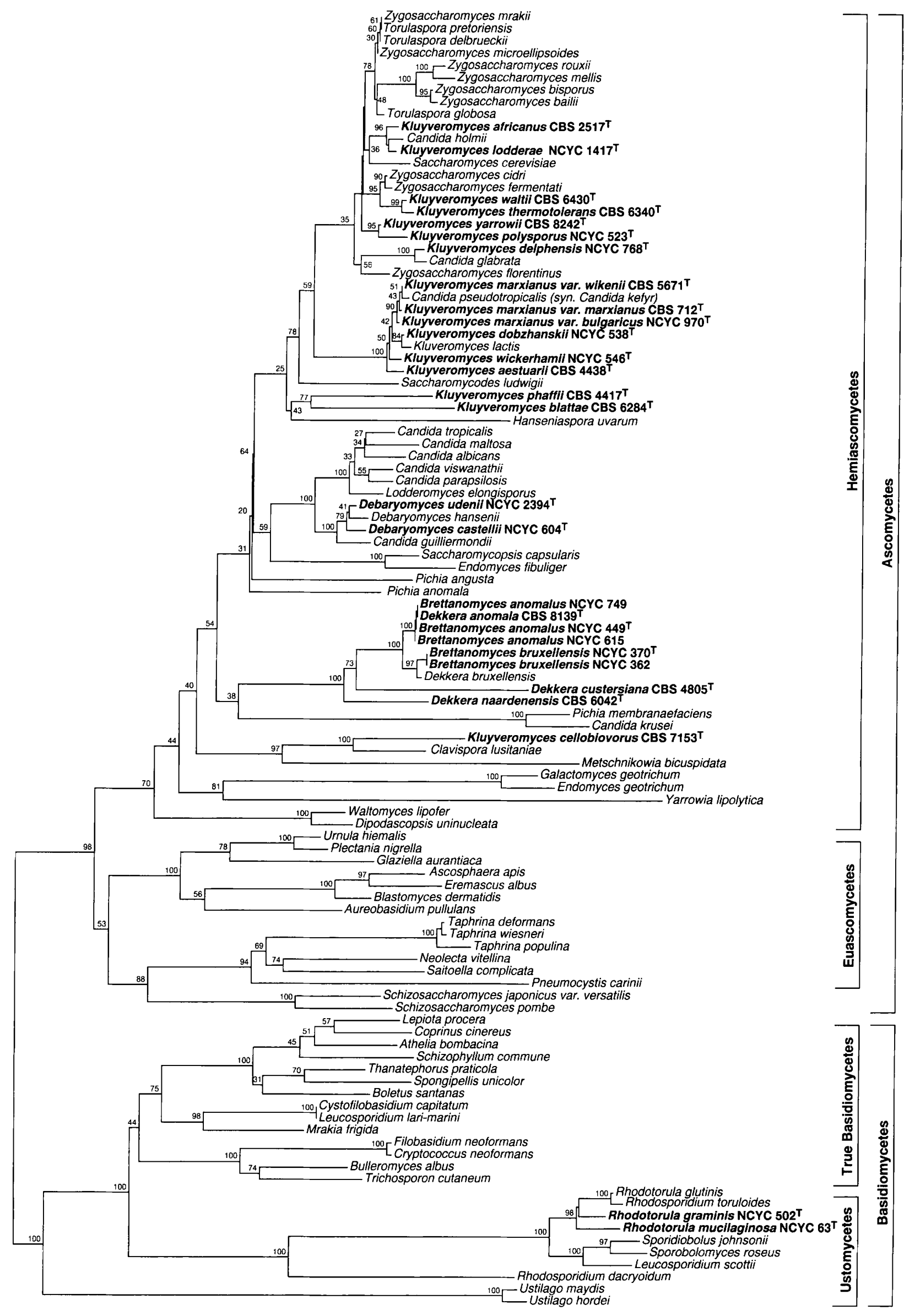


TABLE 3. Levels of $18 \mathrm{~S}$ rRNA gene sequence similarity for Brettanomyces and Dekkera strains

\begin{tabular}{|c|c|c|c|c|c|c|c|c|c|c|}
\hline \multirow[b]{2}{*}{ Organism } & \multicolumn{10}{|c|}{$\% 18 \mathrm{~S}$ rRNA sequence similarity } \\
\hline & 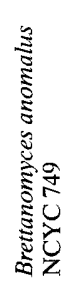 & 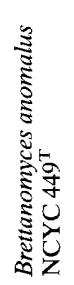 & 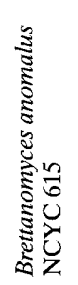 & 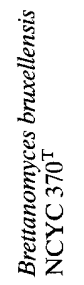 & 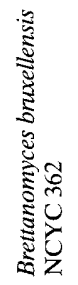 & 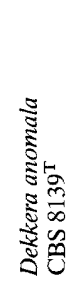 & 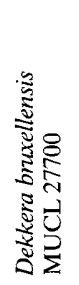 & 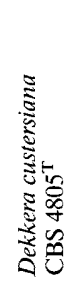 & 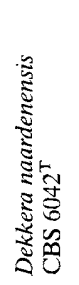 & 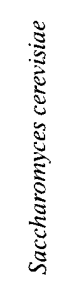 \\
\hline Brettanomyces anomalus NCYC 749 & 100 & 100 & 100 & 99.5 & 99.5 & 99.9 & 99.2 & 95.4 & 96.6 & 93.4 \\
\hline Brettanomyces anomalus NCYC $449^{\mathrm{T}}$ & & 100 & 100 & 99.5 & 99.5 & 99.9 & 99.2 & 95.0 & 96.6 & 93.5 \\
\hline Brettanomyces anomalus NCYC 615 & & & 100 & 99.5 & 99.5 & 99.9 & 99.2 & 95.3 & 96.6 & 93.4 \\
\hline Brettanomyces bruxellensis NCYC $370^{\mathbf{T}}$ & & & & 100 & 100 & 99.4 & 99.6 & 94.8 & 96.4 & 93.6 \\
\hline Brettanomyces bruxellensis NCYC 362 & & & & & 100 & 99.4 & 99.6 & 95.4 & 96.3 & 93.6 \\
\hline Dekkera anomala $\mathrm{CBS} 8139^{\mathrm{T}}$ & & & & & & 100 & 99.3 & 95.1 & 96.5 & 93.3 \\
\hline Dekkera bruxellensis MUCL 27700 & & & & & & & 100 & 95.1 & 96.4 & 93.4 \\
\hline Dekkera custersiana CBS $4805^{\mathrm{T}}$ & & & & & & & & 100 & 95.1 & 91.7 \\
\hline Dekkera naardenensis CBS $6042^{\mathrm{T}}$ & & & & & & & & & 100 & 93.4 \\
\hline Saccharomyces cerevisiae & & & & & & & & & & 100 \\
\hline
\end{tabular}

guilliermondii (teleomorph, Pichia guilliermondii) is a close phylogenetic relative (levels of sequence similarity; 99 to $99.2 \%$; bootstrap value, $100 \%$ ) of these Debaryomyces species. Five Candida species (Candida albicans, Candida maltosa, Candida parapsilosis, Candida tropicalis, and Candida viswanathii) and Lodderomyces elongisporus formed a phylogenetically separate, but nevertheless highly significant, association (intergroup levels of sequence similarity, approximately 96.6 to $98.1 \%$; bootstrap value, $100 \%$ ) with the Debaryomyces-Candida guilliermondii cluster.

Genus Kluyveromyces. It was evident from the results of the phylogenetic analysis that the genus Kluyveromyces is not a monophyletic group and that several species are intermixed with members of other ascomycetous genera (Fig. 1). A total of 14 of the Kluyveromyces strains compared fell into two major phylogenetic clusters, whereas 3 strains formed relatively distinct lines. Cluster 1 comprised nutritionally restricted species, some of which produce more than four spores per ascus
(Kluyveromyces africanus, Kluyveromyces delphensis, Kluyveromyces lodderae, Kluyveromyces polysporus, and Kluyveromyces yarrowii) $(15,25)$, the high-G+C-content species Kluyveromyces thermotolerans and Kluyveromyces waltii (5), and species belonging to the genera Saccharomyces, Torulaspora, and $Z y$ gosaccharomyces. Within this group several very significant phylogenetic associations between Kluyveromyces species were apparent. For example, consistent with the results of an rDNA restriction analysis $(21), K$. polysporus and $K$. yarrowii were found to be genealogically closely related (level of sequence similarity, 99.4\%), as were $K$. africanus and $K$. lodderae (level of sequence similarity, 99.5\%) (Table 5). We also found that Candida holmii (teleomorph, Saccharomyces exiguus) has a close phylogenetic affinity (levels of sequence similarity, 99.1 to $99.3 \%$ ) with the latter two organisms. Similarly, we found that $K$. thermotolerans and $K$. waltii are highly related (level of sequence similarity, $99.7 \%$ ). The close phylogenetic affinity between the last two species correlates well with the results of

TABLE 4. Levels of $18 \mathrm{~S}$ rRNA gene sequence similarity for Debaryomyces species and their close relatives

\begin{tabular}{|c|c|c|c|c|c|c|c|c|c|c|c|}
\hline \multirow[b]{2}{*}{ Organism } & \multicolumn{11}{|c|}{$\% 18 \mathrm{~S}$ rRNA gene sequence similarity } \\
\hline & 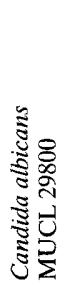 & 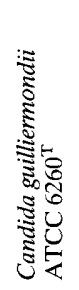 & 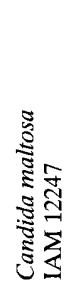 & 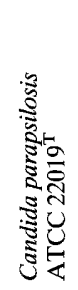 & 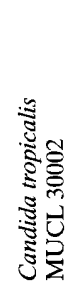 & 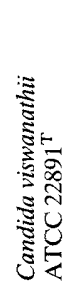 & 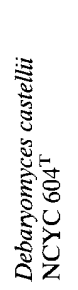 & 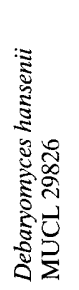 & 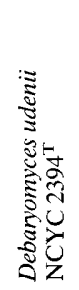 & 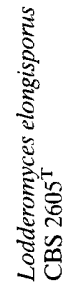 & 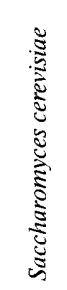 \\
\hline Candida albicans MUCL 29800 & 100 & 96.1 & 97.4 & 98.3 & 98.5 & 98.8 & 96.6 & 96.6 & 96.6 & 97.7 & 95.2 \\
\hline Candida guilliermondii ATCC $6260^{\mathrm{T}}$ & & 100 & 96.3 & 97.7 & 97.0 & 98.2 & 99.0 & 99.2 & 99.2 & 96.7 & 95.4 \\
\hline Candida maltosa IAM 12247 & & & 100 & 97.9 & 97.9 & 98.6 & 97.0 & 96.8 & 97.1 & 97.1 & 93.8 \\
\hline Candida parapsilosis ATCC $22019^{\mathrm{T}}$ & & & & 100 & 99.0 & 99.3 & 98.0 & 98.0 & 97.9 & 98.7 & 95.5 \\
\hline Candida tropicalis MUCL 30002 & & & & & 100 & 99.5 & 97.8 & 97.7 & 98.1 & 98.7 & 95.3 \\
\hline Candida viswanathii ATCC $22891^{\mathrm{T}}$ & & & & & & 100 & 98.0 & 98.1 & 98.0 & 98.6 & 95.5 \\
\hline Debaryomyces castellii NCYC $604^{\mathrm{T}}$ & & & & & & & 100 & 99.2 & 99.6 & 97.8 & 95.2 \\
\hline Debaryomyces hansenii MUCL 29826 & & & & & & & & 100 & 99.4 & 97.6 & 95.1 \\
\hline Debaryomyces udenii NCYC $2394^{\mathrm{T}}$ & & & & & & & & & 100 & 97.8 & 95.5 \\
\hline Lodderomyces elongisporus CBS $2605^{\mathrm{T}}$ & & & & & & & & & & 100 & 95.2 \\
\hline Saccharomyces cerevisiae & & & & & & & & & & & 100 \\
\hline
\end{tabular}



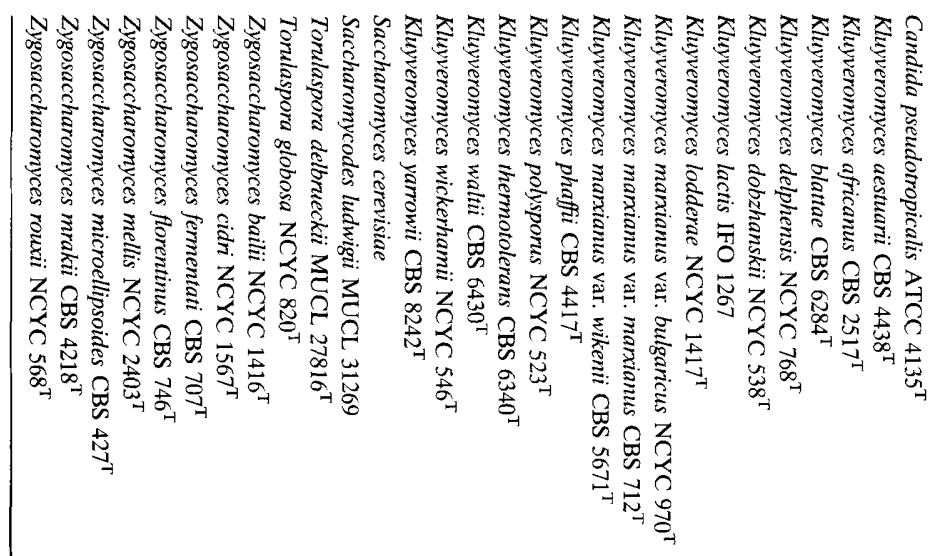

$8 \stackrel{8}{8}$

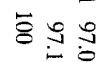

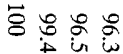

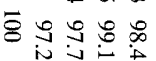

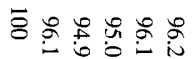

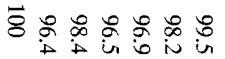

$\overline{8} \div$.

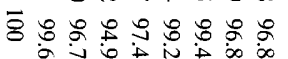

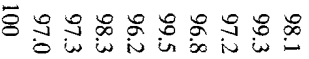

$\overline{8} \div .8 \%$

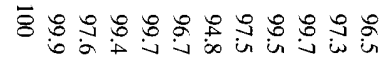

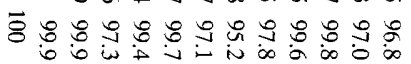

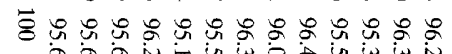

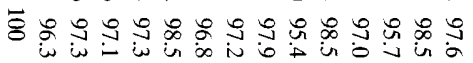

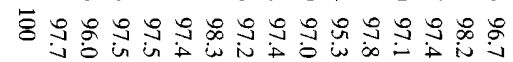

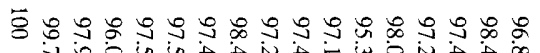

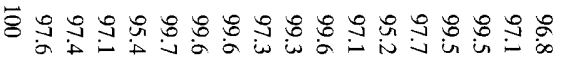

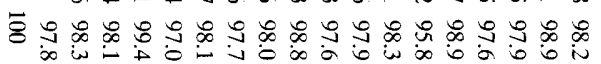

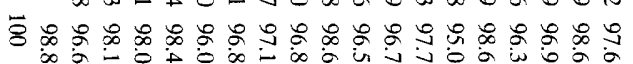

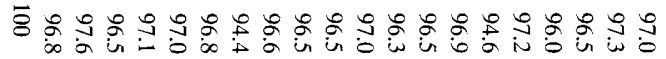

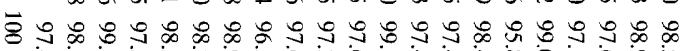

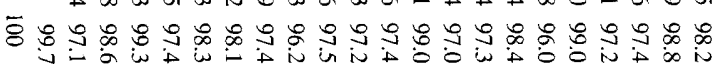

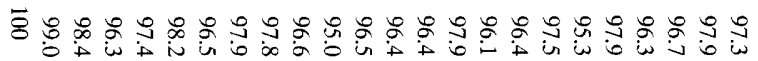

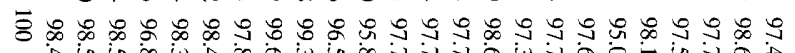

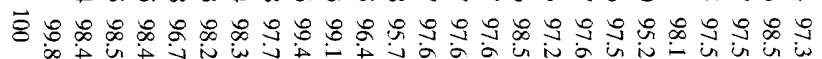

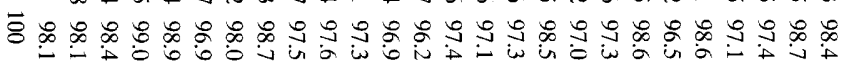
$\overline{8}$ \%

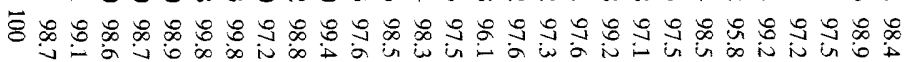
$\overline{8} 8 \%$

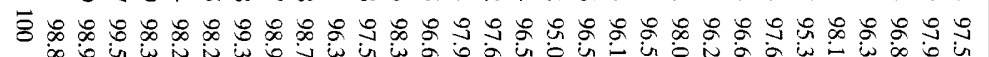

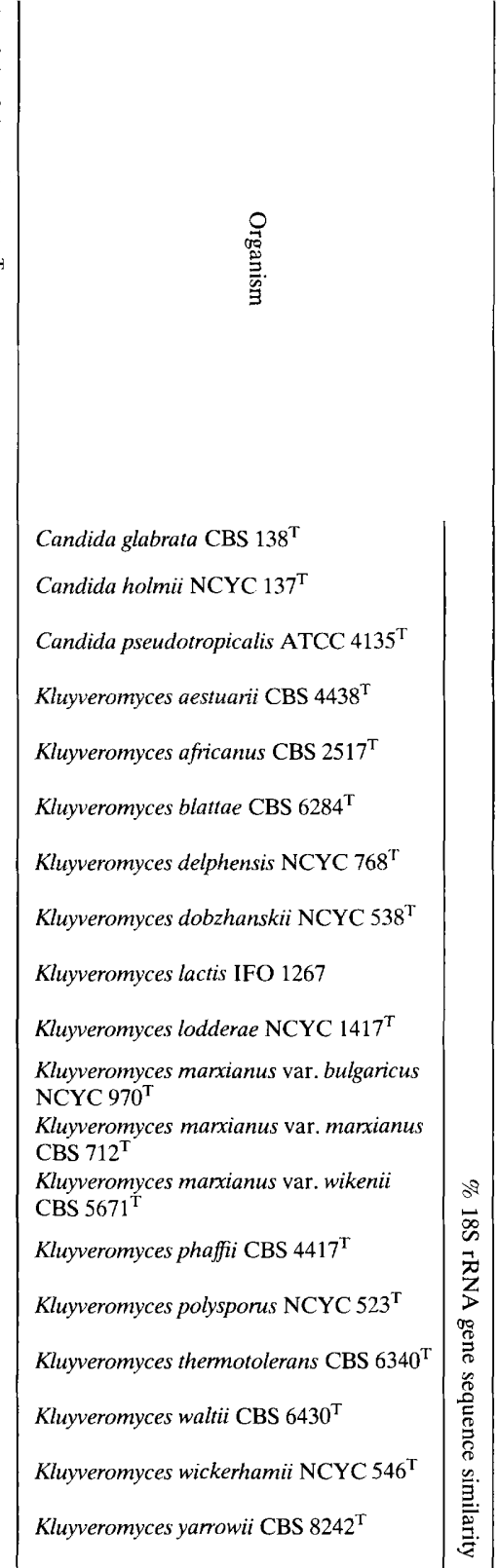

Saccharomyces cerevisiae

Saccharomycodes ludwigii MUCL 31269 Torulaspora delbrueckii MUCL $27816^{\mathrm{T}}$ Torulaspora globosa NCYC $820^{\mathrm{T}}$

Zygosaccharomyces bailii NCYC $1416^{\mathrm{T}}$ Zygosaccharomyces cidri $\mathrm{NCYC} 1567^{\mathrm{T}}$ Zygosaccharomyces fermentati CBS $707^{\mathrm{T}}$ Zygosaccharomyces forentinus $\mathrm{CBS} 746^{\mathrm{T}}$ Zygosaccharomyces mellis $\mathrm{NCYC} 2403^{\mathrm{T}}$ Zygosaccharomyces microellipsoides CBS $427^{\mathrm{T}}$

Zygosaccharomyces mrakii CBS $4218^{\mathrm{T}}$ Zygosaccharomyces rouxii $\mathrm{NCYC} 568^{\mathrm{T}}$ 
phenotypic and genotypic studies $(5,11)$, including rDNA restriction analyses $(14,21)$. Interestingly, Zygosaccharomyces cidri and Zygosaccharomyces fermentati also exhibited a close (levels of sequence similarity, approximately 99.1 to $99.6 \%$ ) and significant (bootstrap value, $>90 \%$ ) association with $K$. thermotolerans and $K$. waltii. $K$. delphensis did not exhibit a particularly close phylogenetic affinity with any other Kluyveromyces species but did exhibit a highly significant association with Candida glabrata (level of sequence similarity, $99.5 \%$ bootstrap value, $100 \%)$. K delphensis and Candida glabrata share many characteristics, including similar assimilation and fermentation profiles, coenzyme Q compositions, and genomic $\mathrm{G}+\mathrm{C}$ contents $(17,25)$. It is clear from the treeing analysis results that the seven Kluyveromyces species in cluster 1, including $K$. polysporus, the type species of the genus Kluyveromyces, are phylogenetically intermixed with members of the genera Saccharomyces, Torulaspora, and Zygosaccharomyces. The overall levels of $18 \mathrm{~S}$ rRNA sequence similarity for the cluster 1 species are very high (generally $>97 \%$ ). Although there are many significant species associations, as well as considerable internal structure, in this phylogenetic group, it is clear from the branching pattern of the tree that no separation of the genera Kluyveromyces, Saccharomyces, Torulaspora, and Zygosaccharomyces along traditional lines is possible phylogenetically.

Cluster 2 comprised five Kluyveromyces species (Kluyveromyces aestuarii, Kluyveromyces dobzhanskii, Kluyveromyces lactis, Kluyveromyces marxianus [including $K$. marxianus var. marxia$n u s, K$ marxianus var. bulgaricus, and $K$ marxianus var. wikenii], and Kluyveromyces wickerhamii) and Candida pseudotropicalis (Fig. 1). The members of cluster 2 formed a highly related (levels of intragroup sequence similarity, $>99 \%$ ) and significant (bootstrap value, $100 \%$ ) group that was well separated from the cluster 1 organisms and other Kluyveromyces species. These findings are consistent with the results of an rDNA restriction analysis (21). The ability of $K$. dobzhanskii, $K$. lactis, $K$ marxianus, and $K$. wickerhamii to mate in the laboratory ( 9 , $10,24)$ is also consistent with the close affinity of these species. The anamorph-teleomorph relationship between Candida pseudotropicalis (synonym, Candida kefyr) and $K$. marxianus varieties has been demonstrated by DNA reassociation analysis (5) and isoenzyme analysis (22), although there is evidence of heterogeneity in these species $(23,26)$. However, it is absolutely clear from our data that the members of cluster 2 form a phylogenetically coherent group worthy of a distinct genus.

Kluyveromyces blattae and Kluyveromyces phaffii formed distinct lines of descent that were quite separate from each other and from the cluster 1 and 2 species (Fig. 1). The loose association of $K$. blattae, $K$. phaffii, Hanseniaspora uvarum, and other species is not statistically significant, as shown by the relatively low bootstrap values (Fig. 1). The recovery of $K$. blattae as a distinct line is consistent with evidence obtained from mating studies $(9,24)$, DNA reassociation analysis (5), and rDNA restriction mapping $(14,21)$, all of which showed that $K$. blattae is a distantly related species of the genus Kluyveromyces. Using rDNA restriction analysis, Shen et al. (21) recovered $K$. phaffii in the same group as $K$. thermotolerans and $K$. waltii. These authors (21) noted that the position of $K$. phaffi was somewhat uncertain and that this species may occupy an intermediate position between $K$. africanus and $K$. thermotolerans. The results of our analysis of almost complete 18S rRNA gene sequences, however, clearly show that $K$. phaffii is an independent line that is far removed from $K$ africanus, $K$. thermotolerans, and $K$. waltii, all of which are members of phylogenetic cluster 1 (Fig. 1). Irrespective of the taxonomic complexities associated with the intermixing of many Kluyveromyces species with other ascomycetous genera (e.g., the genus Zygosaccharomyces), it is evident from the sequence divergence values and the results of the treeing analysis that both $K$. blattae and $K$. phaffii should be excluded from the genus Kluyveromyces and warrant new separate genera.

Kluyveromyces cellobiovorus CBS $7153^{\mathrm{T}}$ was also found to be phylogenetically far removed from other Kluyveromyces species (Fig. 1). This finding is consistent with the results of an rDNA restriction analysis $(21)$ in which $K$. cellobiovorus formed a line quite separate from other members of the genus Kluyveromyces. $K$. cellobiovorus, which is not known to form ascospores, is conspecific with Candida intermedia. K. cellobiovorus and Candida intermedia exhibit very high levels of nuclear DNA homology $(>90 \%)$ (16). It is evident from the results of our investigation that $K$. cellobiovorus should be excluded from the genus Kluyveromyces. Furthermore, our data show that $K . \mathrm{cel}$ lobiovorus exhibits a highly significant, albeit distant, phylogenetic association with Clavispora lusitaniae (level of sequence similarity, $96.5 \%$; bootstrap value, $100 \%)$.

\section{ACKNOWLEDGMENT}

We are indebted to European Economic Community Agricultural Industrial Research Programme contract CT93-0830 for support.

\section{REFERENCES}

1. Boekhout, T., C. P. Kurtzman, K. O'Donnell, and M. T. Smith. 1994. Phylogeny of the yeast genera Hanseniaspora (anamorph Kloeckera), Dekkera (anamorph Brettanomyces), and Eeniella as inferred from partial 26S ribosomal DNA nucleotide sequences. Int. J. Syst. Bacteriol. 44:781-786.

2. Devereux, J., P. Haeberli, and D. Smithies. 1984. A comprehensive set of sequence analysis programs for the VAX. Nucleic Acids Res. 12:387-395.

3. Felsenstein, J. 1993. PHYLIP: phylogenetic inference package, version 3.5. University of Washington, Seattle.

4. Feng, D. F., and R. F. Doolittle. 1987. Progressive sequence alignment as a prerequisite to correct phylogenetic trees. J. Mol. Evol. 35:351-360.

5. Fuson, G. B., H. L. Presley, and H. J. Phaff. 1987. Deoxyribonucleic acid base sequence relatedness among members of the yeast genus Kluyveromyces. Int. J. Syst. Bacteriol. 37:371-379.

6. Hendriks, L., A. Goris, Y. Van de Peer, J.-M. Neefs, M. Vancanneyt, K. Kersters, J.-F. Berny, G. L. Henebert, and R. De Wachter. 1992. Phylogenetic relationships among ascomycetes and ascomycete-like yeasts as deduced from small ribosomal subunit RNA sequences. Syst. Appl. Microbiol. 15:98-104.

7. Hutson, R. A., D. E. Thompson, and M. D. Collins. 1993. Genetic interrelationships of saccharolytic Clostridium botulinum types B, E and F and related clostridia as revealed by small-subunit rRNA gene sequences. FEMS Microbiol. Lett. 108:103-110.

8. James, S. A., M. D. Collins, and I. N. Roberts. 1994. Genetic interrelationship among species of the genus Zygosaccharomyces as revealed by smallsubunit rRNA gene sequences. Yeast 10:871-881.

9. Johannsen, E. 1980 . Hybridization studies within the genus Kluyveromyces van der Walt emend. van der Walt. Antonie van Leeuwenhoek J. Microbiol. 46:177-189.

10. Johannsen, E., and J. P. van der Walt. 1978. Interfertility as basis for the delimitation of Kluyveromyces marxianus. Arch. Microbiol. 118:45-48.

11. Kreger-van Rij, N. J. W. 1979. A comparative ultrastructural study of the ascospores of some Saccharomyces and Kluyveromyces species. Arch. Microbiol. 121:53-59.

12. Kurtzman, C. P. 1992. rRNA sequence comparisons for assessing phylogenetic relationships among yeasts (minireview). Int. J. Syst. Bacteriol. 42:1-6.

13. Kurtzman, C. P., and C. J. Robnett. 1991. Phylogenetic relationships among species of Saccharomyces, Schizosaccharomyces, Debaryomyces and Schwanniomyces determined from partial ribosomal RNA sequences. Yeast 7:61-72.

14. Lachance, M.-A. 1989. Restriction mapping of rDNA and the taxonomy of Kluyveromyces van der Walt emend. van der Walt. Yeast 5:S379-S383.

15. Lachance, M.-A. 1993. Kluyveromyces: systematics since 1970. Antonie Leeuwenhoek 63:95-104.

16. Martini, A., and A. Vaughan Martini. 1992. Assignment of Kluyveromyces cellobiovorus nomen nudum to Candida intermedia (Ciferri \& Ashford) Langeron et Guerra. Antonie Leeuwenhoek 61:57-60.

17. Meyer, S. A., D. G. Ahearn, and D. Yarrow. 1984. Genus 4. Candida Berhout, p. 585-844. In N. J. W. Kreger-van Rij (ed.), The yeasts: a taxonomic study, 3rd ed. Elsevier Science Publishers B. V., Amsterdam.

18. Molina, F. I., P. Shen, and S.-C. Jong. 1993. Validation of the species concept in the genus Dekkera by restriction analysis of genes coding for rRNA. Int. J. Syst. Bacteriol. 43:32-35. 
19. Philippsen, P., A. Stotz, and C. Scherf. 1991. DNA of Saccharomyces cerevisiae. Methods Enzymol. 194:169-182.

20. Sambrook, J., E. F. Fritsch, and T. Maniatis. 1989. Molecular cloning: a laboratory manual, 2nd ed., p. 6.55-6.56. Cold Spring Harbor Laboratory Press, Cold Spring Harbor, N.Y.

21. Shen, P., S.-C. Jong, and F. I. Molina. 1994. Analysis of ribosomal DNA restriction patterns in the genus Kluyveromyces. Antonie Leeuwenhoek 65 : 99-105.

22. Sidenberg, D. G., and M.-C. Lachance. 1986. Electrophoretic isoenzyme variation in Kluyveromyces populations and revision of Kluyveromyces marxianus (Hansen) van der Walt. Int. J. Syst. Bacteriol. 36:94-102.

23. Sor, R., and H. Fukuhara. 1989. Analysis of chromosomal DNA patterns of the genus Kluyveromyces. Yeast 5:1-10.

24. van der Walt, J. P., and E. Johannsen. 1979. A comparison of interfertility and in vitro DNA-DNA reassociation as criteria for speciation in the genus Kluyveromyces. Antonie van Leeuwenhoek J. Microbiol. 45:281-291.

25. van der Walt, J. P., and E. Johannsen. 1984. Genus 13. Kltrveromyces, p. 224-251. In N. J. W. Kreger-van Rij (ed.), The yeasts: a taxonumic study, 3rd ed. Elsevier Science Publishers B. V., Amsterdam.

26. Viljoen, B. C., J. L. F. Kock, and D. J. Coetzee. 1988. Orthogonal-fieldalternation gel electrophoresis banding patterns of some asporogenous yeasts and their respective ascosporogenous states. Syst. Appl. Microbiol. 10: $228-230$.

27. Wilmotte, A., Y. Van de Peer, A. Goris, S. Chapelle, R. De Baere, B. Nelissen, J.-M. Neefs, G. L. Hennebert, and R. De Wachter. 1993. Evolutionary relationships among higher fungi inferred from small ribosomal subunit RNA sequence analysis. Syst. Appl. Microbiol. 16:436-444.

28. Woese, C. R. 1987. Bacterial evolution. Microbiol. Rev. 51:221-271.

29. Yamada, Y., K. Maeda, and K. Mikata. 1994. The phylogenetic relationships of Rhodosporidium dacryodum. Fell, Hunter et Tallman based on the partial sequences of $18 \mathrm{~S}$ and $26 \mathrm{~S}$ ribosomal RNAs: the proposal of Sakaguchia gen. nov., a heterobasidiomycetous yeast genus. Biosci. Biotechnol. Biochem. 58: 99-103.

30. Yamada, Y., M. Matsuda, K. Maeda, and K. Mikata. 1994. The phylogenetic relationships of species of the genus Dekkera van der Walt based on the partial sequences of $18 \mathrm{~S}$ and $26 \mathrm{~S}$ ribosomal RNAs (Saccharomycetaceae). Biosci. Biotechnol. Biochem. 58:1803-1808.

31. Yamada, Y., T. Nagahama, and I. Banno. 1991. The molecular phylogeny of the Q9-equipped ascomycetous teleomorphic yeast genus Debaryomyces Lodder et Kreger-van Rij based on the partial sequences of $18 \mathrm{~S}$ and $26 \mathrm{~S}$ ribosomal ribonucleic acids. J. Gen. Appl. Microbiol. 37:277-288. 